\title{
POBOLJŠANJE STEPENA ISTRAŽENOSTI TERENA NA TRASI MAGISTRALNOG PUTA FOČA - HUM
}

Neđo Đurić ${ }^{1}$

УДК: 550.8.04:625.711.1

DOI:10.14415/konferencijaGFS 2015.046

Rezime: Magistralni put Foča - Hum predstavlja jedinu trasu važnijiih puteva koja nije revitalizovana niti poboljšavana od njene izgradnje. Veća frekventnost sobraćaja, kao $i$ potreba bržeg povezivanja Albanije preko Crne Gore $i$ Bosne i Hercegovine sa centralnom Evropom zahijeva poboljšanje kvaliteta postojeće saobraćajnice u svim njenim segmentima. Dužina trase saobraćajnice je oko $17 \mathrm{~km}$, a karakteriše dosta suženih dijelova i oštrih krivina, zbog čega će u nekim dijelovima biti proširena, a krivine ispravljene. Na krajnjem dijelu trase preko mosta na rijeci Tari uspostavit će se povezivanje sa istom saobraćajnicom, koja dalje ide preko Crne Gore do Albanije.

Osamdesetih godina započeta su istraživanja za trasu saobraćajnice, kao i izgradnju energetskih objekata u gornjem slivu rijeke Drine. Nivo istraženosti za trasu saobraćajnice nije odgovarajući, zbog čega je neophodno povećati stepen istraženosti duž trase koja je usklađena sa prostorno planskom dokumentacijom. Složenost geološke građe $i$ značaj saobraćajnice $i$ objekata na trasi zahtijevaju detaljna geološka istraživanja, kojim će se definisati karakteristike terena.

Ključne reči: trasa saobraćajnice,objekti na trasi, karakteristike terena, istraženost terena

\section{UVOD}

Putna saobraćajnica od Foče do državne granice sa Crnom Gorom je jedna od rijetkih saobraćajnica koja pedesetak godina nije revitalizovana iako se protok saobraćaja svake godine povećavao. Njen značaj nije osporavan, ali vremena koja su prolazila nisu u dovoljnoj mjeri dala prostora da se seobraćajnica uskladi sa dinamikom saobraćaja. Početkom devedesetih godina provedena su određena geološka istraživanja terena i utvrđena nova trasa saobraćajnice usklađena sa podizanjem nivoa akumulacionog jezera Buk Bijela u Foči, kao i karakteristikama terena. Na početnom dijelu od Foče urađeno je nekoliko objekata koji se nalaze na trasi saobraćajnice, ali događaji početkom devedesetih godina zaustavili su sve aktivnosti po tom pitanju.

Početkom XXI vijeka ponovo je započeta aktivnost oko poboljšanja kvaliteta saobraćajnice, koja je sada dobila međunarodni značaj. Ista se nalazi na glavnoj putnoj mreži regiona, projektovanoj kao E - ruta (E762), koja ide od Albanije i povezuje sa

\footnotetext{
${ }^{1}$ Prof. dr Neđo Đurić, Univerzitet u Novom Sadu, Građevinski fakultet Subotica, Kozaračka 2a, Srbija. e.mail.nedjo@tehnicki-institut.com
} 
International conference

Contemporary achievements in civil engineering 24. April 2015. Subotica, SERBIA

autoputem koridor Vc kod Sarajeva. To je direktna veza i najkraći put između Bosne i Hercegovine i Albanije koji ide preko Crne Gore, Bosne i Hercegovine do Centralne Evrope. Poboljšano stanje saobraćajnice će omogućiti bolju regionalnu integraciju u jugoistočnoj Evropi, a smanjiće udaljenost na potezu Albanija - Centralna Evropa.

U sklopu poboljšanja kvaliteta saobraćajnice izvršeno je upoređivanje i komparativna evaluacija nekoliko alternativnih putnih trasa, te je odabrana trasa koja najviše odgovara karakteristikama terena, a može se uklopiti u prostorno plansku dokumentaciju. Analizirana su ranija istraživanja terena na ovom prostoru, koja su vršena za različite svrhe, te data ocjena stepena dosadašnje istraženosti i prijedlog daljih istraživanja duž trase puta i objekata na trasi [1,2,3]. Rezultati svih istraživanja i ispitivanja će predstavljati podlogu za izradu tehničke dokumentacije.

\section{OSNOVNE KARAKTERISTIKE TRASE SAOBRAĆAJNICE}

Magistralni put se pruža duž desne strane rijeke Drine, presijecajući manje potoke, na pojedinim mjestima usijeca se u padine ili premoštava veća ulegnuća. Generalno posmatrano teren duž koga prolazi postojeća trasa saobraćajnice koja se prostire približno pravolinijski je jako složen. U cilju poboljšanja kvaliteta puta, neophodno je izvršiti njegovu rekonsrukciju, tako što će se u nekim dijelovima trasa proširiti, a negdje ispraviti, slika 1 .

Nadmorska visina na početnoj stacionaži je 410,0 m, a na krajnjoj 480,0 m. Između njih teren se duž trase saobraćajnice lagano talasa, sa blagim nagibom u pravcu riječnog toka. Reljef terena karakteriše padinu promjenljivog nagiba, čiji je donji dio u koritu rijeke Drine. Trasa saobraćajnice se najvećim dijelom usijeca u padinu. Udaljenost trase od korita rijeke je promjenljiva, ali je postavljena tako da bude iznad kote $436 \mathrm{~m}$, koja je iznad maksimalno projektovanog nivoa buduće akumulacije HE Buk Bijela [4,5].

Trasu saobraćajnice presijecaju manji vodotoci, koji se mogu nazvati potocima. Prisutan je veći broj manjih bezimenih potoka i dva veća potoka. Velike poplave u posljednjih nekoliko godina zahtijevaju posebne analize proticajaj rijeke Drine u dijelu od ušća Tare i Pive, do Broda kod Foče, sa aspekta njihovog uticaja na trasu planirane saobraćajnice. U geološkom smislu teren nije nepoznat. Mnogi geolozi i razni istraživači su prolazili dolinom rijeke Drine i ostavljali razne zapise, od kojih su neki vezani i za geološke karakteristike terena. Novija istraživanja vezana su za šezdesete godine u sklopu izrade Osnovne geološke karte SFRJ 1 : 100000, kao i za potrebe izgradnje energetskih objekata. Rijeka Drina i njen sliv u gornjem dijelu, posebno su geološki izučavani za potrebe akumulacije Buk Bijela, a kasnije i izrade magistralnog puta Foča - Hum Plužine. Provedena su djelimična istraživanja za nekoliko alternativnih profila iznad kote $500 \mathrm{mnm}$, ali o njima nema podataka. 


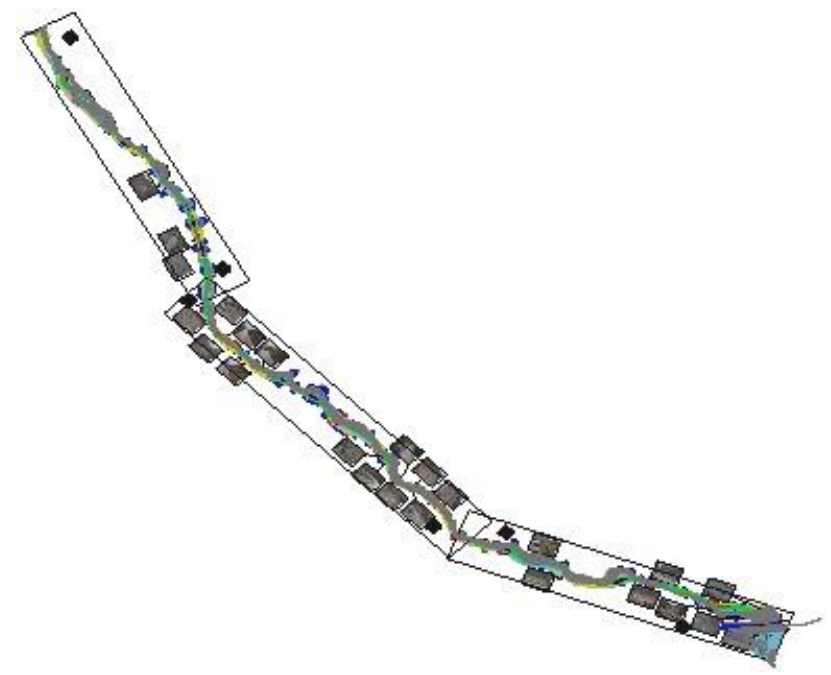

Slika 1. Trasa saobraćajnice Foča-Hum

\section{GEOLOŠKE I INŽENJERSKOGEOLOŠKE KARAKTERISTIKE TERENA}

Geološka građa posmatrana za nešto širi dio terena karakteriše sedimente donjeg karbona koji je razvijen dolinom rijeke Drine. Predstavljen je pješčarima, filitičnim škriljcima, listastim glincima, liditima i liditskim brečama, kvarcnim žicama, i pločastim mermeniziranim krečnjacima.

Ostali sedimenti su manje zastupljeni i predstavljeni su permotrijaskim i trijaskim sedimentima. Uglavnom prate dio terena uzvodno uz rijeku Drinu. Predstavljeni su crvenim i sivim kvarcnim pješčarima, crvenim kvarcnim konglometarima, liditima i liditskim brečama, te mermeniziranim krečnjacima.

$\mathrm{Na}$ jugoistočnom dijelu terena od ušća rijeka Tare i Pive, zastupljeni su kvartarni sedimenti, kao i na manjem prostoru nizvodno na desnoj obali rijeke Drine. Takođe ovi sedimenti su prisutni u dolini rijeka od ušća Sutjeske u Drinu, pri čemu su više zastupljeni na lijevoj obali rijeke Drine. Predstavljeni su riječnom terasom $\left(\mathrm{t}_{1}\right)$, moćnosti nekoliko metara, a koju izgrađuju sedimenti sa valuticama pretežno krečnjaka, rjeđe valuticama pješčara, rožnjaca i magmatskih stijena. Valutice su dijagenetskim procesima vezane i prelaze u konglomerate. U dijelu terena od ušća rijeka Pive i Tare pa do ušća rijeke Sutjeske u Drinu prisutni su sipari, koji su u geološkom stubu postavljeni između niže riječne terase $\left(t_{1}\right)$ i aluvijuma $(\mathrm{al}),[6]$.

Neposredna okolina duž trase saobraćajnice pripada tektonskoj jedinici Ustikoline, koja dijelom ide prema jugu u obliku klina duž rasjeda Čurovo - Brod na Drini i dopire do Šćepan polja. U ovoj jedinici u dijelu istražnog prostora zastupljeni su donji karbon, permotrijas, te donji i srednji trijas. U donje karbonskim sedimentima nije zapažen karbonatni razvoj, a elementi fliša veoma su rijetki. Takođe nisu prisutna intenzivna 
International conference

Contemporary achievements in civil engineering 24. April 2015. Subotica, SERBIA

boranja. Granica između donjeg karbona i permotrijasa je diskordantna ili rasjednog karaktera. Stiče se dojam da su permotrijaski sedimenti ove jedinice nešto niži u odnosu na tektonske jedinice u susjedstvu.

Duž trase saobraćajnice zastupljeni su proluvijalno deluvijalni naslage, predstavljeni drobinskim materijalom kao što su pješčari, škriljci, krečnjaci sa pjeskovito-glinovitom ispunom. Teren je uslovno stabilna padina sa povremenim aktiviranjem klizišta $u$ prirodnim i izmijenjenim uslovima. Klizišta se javljaju u strmijim dijelovima padina i dijelovima terena gdje došlo do određenih inženjerskih zahvata, pri čemu su narušeni prirodni uslovi ravnoteže $[2,5,6,7]$.

\section{POBOLJŠANJE STEPENA ISTRAŽENOSTI TERENA DUŽ TRASE SAOBRAĆAJNICE}

Postojeća trasa saobraćajnice će se proširiti, a u nekim dijelovime ispraviti. Na granici sa Crnom Gorom izgradiće se novi most preko rijeke Tare i granični prelaz. Uslovna stabilnost terena koja je uglavnom prisutna duž trase će biti narušena novim inženjerskim zahvatima. Sve to zahtijeva detaljnije sagledavanje karakteristike terena duž cijele trase, kao i na dijelovima gdje su planirani objekti na trasi.

U fazi pripreme za izbor konačne trase saobraćajnice, razmatrano je nekoliko varijanti, sa aspekta uklapanja u prostorno plansku dokumentaciju koja je usklađena sa korištenjem energetskih potencijala na ovom području. Odabrana je varijanta, koja pored navedenog kriterijuma, najmanje narušava prirodno stanje terena, te zahtijeva minimalan broj objekata na trasi.

U ovoj fazi istraživanja prethodno je analizirana postojeća dokumentacija koja obuhvata sve vidove istraživanja, a dotiču se trase saobraćajnice. Detaljnije posmatrano trasa saobraćajnice je podijeljena u tri dijela. Na početnom dijelu trase ima najviše podataka o inženjerskogeološkim istraživanjima i provedenim istražnim radovima na lokaciji mostova. Ostala istraživanja koja su provedena za potrebe izgradnje akumulacije Buk Bijela, korišena su za generalno sagledavanje geološke građe, obzirom da se odnose na padine koje su hipsometrijski niže u odnosu na trasu saobraćajnice. Analizirani podaci su dali osnovna saznanja o karakteristikama terena, ali ne dovoljna za izradu projektne dokumentacije.

$\mathrm{Na}$ ovom dijelu trase izvedeno je 5 istražnih raskopa raspoređenih na udaljenosti od 1 $\mathrm{km}$. Iskop je vršen ručno do supstrata terena ili do zone blokova u kori raspadanja stjena supstrata. U jamama je vršeno detaljno inženjerskogeološko kartiranje zidova raskopa, gdje je registrovano stanje stijenske mase sa posebnim osvrtom na litološki sastav i granulaciju eluvijalno-deluvijalnih materijala, kao i na dubinu i svojstva osnovne stjenske mase [6]. Iz jama su uzimani uzorci za laboratorijska ispitivanja. Ipak to nisu dovoljna istraživanja, tako je neohodno povećati stepen istraženosti terena sa dodatnim istražnim radovima.

$\mathrm{Na}$ srednjem dijelu trase ranije su urađena detaljna geološko-geotehnička istraživanja kako za trasu puta tako i za vijadukte, a manjim dijelom za klizišta. Izbušeno je ukupno $167,7 \mathrm{~m}$ na 17 geomehaničkih bušotina koje su locirane za potrebe projektovanja trase preko stabilnih terena i klizišta. Takođe na ovom dijelu trase tokom 1991. godine vršena

\section{2}


Међународна конференција

Савремена достигнућа у грађевинарству 24. април 2015. Суботица, СРБИЈА

su bušenja na lokacijama tada planiranih 16 mostova čije se lokacije ne poklapaju sa lokacijama novog prijedloga trase.

$\mathrm{Na}$ krajnjem dijelu trase nije bilo namjenskih istraživanja terena. Za opštu ocjenu geoloških uslova terena korištena je geološka dokumentacija koja se odnosila na Osnovna geološka istraživanja čiji su rezultati prikazani na Osnovnoj geološkoj karti R 1:100 000, list Foča. Manji dio područja zahvaćen je detaljnim istraživanjima za potrebe izgradnje akumulacije i brane Buk Bijela, ali nije bila dostupna za proučavanje.

Tokom inženjerskogeološkog kartiranja terena i izvođenja istražnih radova uzeti su uzorci za laboratorijska ispitivanja, nakon čega je urađena kabinetska obrada rezultata i preliminarni elaborat [6]. Analizirani rezultati dali su uvid u složenost geološke građe terena duž trase saobraćajnice, što zahtijeva veći stepen istraženosti, odnosno detaljnije proučavanje karakteristika terene do nivoa potrebnog za izradu projektne dokumentacije $[8,9]$. Neophodno je detaljnije sagledati:

- geološke, geotehničke i hidrogeološke karakteristike terena duž trase saobraćajnice

- izdvojiti zone terena po stepenu stabilnosti u prirodnim uslovima i uslovima izmijenjene prirodne travnoteže usljed izvođenja radova tokom izrade saobraćajnice i objekata na njenoj trasi

- prisustvo klizišta i eventualni razvoj novih tokom izgradnje i eksploatacije saobraćajnice

- geotehničke uslove izvođenja objekata na trasi saobraćajnice, kao što su uslovi iskopa, temeljenja, osiguranja pri izvođenju radova i mjere opasnosti tokom rada

- izbor geotehničkih parametara tla i stijena, analize stabilnosti nasipa, usjeka, zasjeka, blokova

- način i dubinu temeljenja objekata, nosivost temeljnog tla, odnosno stijena, te veličine slijeganja

- eventualne pojave podzemnih voda i njihov značaj pri izvođenu radova i eksploataciji saobraćajnice

Postavljeni zahtjevi i složenost terena na trasi saobraćajnice, kao i prisustvo većeg broja građevinskih objekata, od mostova, propusta i potpornih zidova, zahtijeva veći i raznovrsniji obim terenskih radova i laboratorijskih ispitivanja, koji se sastoje $u$ sljedećem $[10,11,12]$ :

- detaljno geološko kartiranje terena gdje će se sagledati geološke, inženjerskogeološke, hidrogeološke i geomorfološke karaktersitike duž trase puta u širini $200,0 \mathrm{~m}$, po $100,0 \mathrm{~m}$ sa jedne i druge strane

- geofizička istraživanja za definisanje granica deluvijalnih naslaga, eluvijalne raspadine i osnovnih stijenskih masa, te definisanjem seizmičnosti buduće saobraćajnice za potrebe zemljotresnog proračuna objekata, nestabilnih terena, nagiba usjeka i zasjeka, potpornih zidova i trupa puta

- izrada 237 istražnih bušotina dubine od 6,0 - 15,0 m, ukupne dubine 1953,0 m, gdje su bušotine na trasi dubine $6,0 \mathrm{~m}$, a na objektim od $8,0-15,0 \mathrm{~m}$ 
International conference

Contemporary achievements in civil engineering 24. April 2015. Subotica, SERBIA

- izrada 86 raskopa dubine 2,0 - 4,0 m, ukupne dubine 263,0 m

- detaljno geološko kartiranje jezgra bušotine i zidova raskopa

- izvođenje opita Standardne dinamičke penetracije SPT, ukupno 454

- izvođenje opita vodopropusnosti tla metodom Lefranc, ukupno 9

- uzimanje poremećenih i neporemećenih uzoraka tla i stijena, ukupno 773, od toga za tla 340 uzoraka

- laboratorijska ispitivanja tla i stijena sa određivanjem sljedećih parametara:

* Na uzorcima tla:

- određivanje zapreminske težine tla (čvrstih čestica, suhe i vlažne)

- određivanje prirodne vlažnosti tla

- određivanje Atterbergovih granica

- određivanje granulometrijskog sastava

- određivanje sadržaja organskih materija

- određivanje bubrenja

- određivanje stišljivosti tla (edometarski opit)

- određivanje čvrstoće tla direktnim smicanjem

- određivanje optimalnog sadržaja vode (Proctorov opit)

- određivanje Kalifornijskog indeksa nosivosti (CBR)

* Na uzorcima stijena:

- određivanje zapreminske težine stijene

- određivanje jednoosne pritisne čvrstoće

- određivanje čvrstoće na istezanje

- određivanje tačkaste pritisne čvrstoće, PLT

- određivanje Modula deformacija, Modula elastičnosti i Poassonovog koeficijenta, brzine elastičnih $\mathrm{V}_{\mathrm{p}} \mathrm{i} \mathrm{V}_{\mathrm{s}}$ talasa

Planirana istraživanja $\mathrm{i}$ ispitivanja vezana su za ranije urađena istraživanja terena $\mathrm{i}$ dokumentaciju koja je bila dostupna. Ukoliko do početka istraživanja terena bude dostupna neka dokumentacija koja pokazuje da su na ovoj trasi izvedena određena istraživanja, koja daju reprezentativne podatke, obim terenskih i laboratorijskih radova će se smanjiti.

Rezultati proučavanja dokumentacije, provedenih terenskih istraživanja i laboratorijskih ispitivanja uz kabinetsku obradu podataka, dovoljna su osnova za izradu kompletne projektne dokumentacije za trasu saobraćajnice i objekata na trasi.

\section{ZAKLJUČAK}

Magistralni put Foča - Hum je jedna od važnijih saobraćajnica koj nije značajnije revitalizovana od vremena njene izgradnje. Velika frekventnost saobraćaja i planovi da se uspostavi brza cesta od Albanje preko Crne Gore do Sarajeva i koridora Vc, a zatim veza ka zemljama Evropske Unije, postavila je ovu saobraćajnicu kao prioritetnu u 
Међународна конференција

Савремена достигнућа у грађевинарству 24. април 2015. Суботица, СРБИЈА

narednom periodu. Kako saobraćajnica povezuje Bosnu i Hercegovinu i Crnu Goru, neophodno je usaglasiti izradu projektne dokumentacje i planove njene revitalizacije.

Postojeća trasa od Foče do Huma u dužini oko 17 km je veoma uska sa mnogo suženih dijelova i oštrih krivina. Zbog toga će se u pojedinim dijelovima ista ne samo proširiti, već i ispraviti, vodeći je na krajnjem dijelu preko rijeke Tare sa mostom i graničnim prelazom.

Nivo projektne dokumentacije koja je rađena osamdesetih godina za pojedine dijelove trase nije na zadovoljavajućem nivou u pogledu definisanja karakteristika terena, odnosno tla i stijena koje izgrađuju teren duž trase saobraćajnice. Dokumentacija je rađena za potrebe izgradnje energetskih objekta, te se ne odnosi u dovoljnj mjeri za trasu, obzirom da obrađuje teren koji je hipsometrijski niži od trase.

Složenost geološke građe terena i značaj saobraćajnice zahtijevaju veći stepen istraženosti terena. U cilju poboljšanja istraženosti terena, a koja se nadovezuje na podatke ranijih straživanja, predložen je odgovarajući program istraživanja, čija realizacija daje dovoljnu osnovu za detaljnije saglegavanje karakteristika terena i kvalitetnu podlogu za izradu ostale projektne dokumentacije.

\section{LITERATURA}

[1] Izmještanje puta Brod n/D - Šćepan Polje, dionica Donji Kopilovi - Mazočki Potok. Faza: Varijante idejnog rješenja. Fond stručne dokumentacije Projektantski zavod za puteve i mostove "Traser", Sarajevo, 1990.

[2] Elaborat o inženjerskogeološkim karakteristikama terena i uslovima formiranja i mjerama sanacije klizišta "Kopilovi" na trasi puta Kopilovi - Šćepan Polje, dionica Kopilovi - Mazočki potok. Fond stručne dokumentacije Projektantski zavod "Traser", Sarajevo, 1991.

[3] Elaborat o izvršenim dopunskim geotehničkim istražnim radovima i ispitivanjima za trasu puta D. Kopilovi - Mazočki Potok, dio km 0+000 - 2+000. Fond stručne dokumentacije Projektantski zavod "Traser", Sarajevo, 1991.

[4] Aktuelizacija Idejnog projekta HE Buk Bijela. Knjiga II - Podloge, Sveska 3 Geomehaničke podloge. Fond stručne dokumentacije. Energoprojekat, Beograd, 1985.

[5] Hidroelektrana Buk Bijela, Glavni project, knjiga1. Brana, Sveska 2. aneks 1. Inženjerskogeološke i geotehničke analize istraživanja. Energoprojekt, Beograd, 1987.

[6] Elaborat o rezultatima inženjerskogeoloških istraživanja u koridoru trase puta M18, dionica Foča - Hum, nivo 1, dio 2. faze Studije izvodljivosti. Fond stručne dokumentacije Tehnički institut Bijeljina, 2011.

[7] Sunarić D. (2000). Klizišta i odroni u gornjem toku Drine. Rudarsko - geološki fakultet Beograd, 2000.

[8] Đurić N. Hidrogeološka i inženjerskogeološka istraživanja. Građevinski fakultet Subotica, Tehnčki institut Bijeljina, 2011.

[9] Žigić I. Hidrogeološka istraživanja. Univerzitet u Tuzli, Tuzla. 2004. 
International conference

Contemporary achievements in civil engineering 24. April 2015. Subotica, SERBIA

[10] Santrač P., Bajić Ž. Problem određivanja intenziteta pritiska leda na konstrukciju. Naučno-stručno savetovanje „Geotehnički aspekti građevinarstva”. Zlatibor. str.399-406. 2011.

[11] Projekat detaljnih geoloških istraživanja "Poboljšanje glavnog puta M18, Brod na Drini (Foča) - Hum”.Tehnički institut Bijeljina, 2011.

[12] Smjernice za projektovanje, građenje, održavanje i nadzor na putevima, knjiga I: Projektovanje, dio 1: Projektovanje puteva, poglavlje 2: Inženjerskogeološka i geotehnička istraživanja i ispitivanja, Direkcija za ceste Federacije BiH i Javno preduzeće "Putevi Republike Srpske“, Sarajevo/Banja Luka, 2005.

\title{
IMPROVING DEGREE OF EXPLORATION FIELD ON THE ROUTE MAIN ROAD FOCA - HUM
}

\begin{abstract}
Summary: Main road Foca - Hum is the only route of major roads that are not improved by revitalized nor of its construction. Increased frequency sobraćaj, and the need for faster connectivity Albania via Montenegro and Bosnia and Herzegovina to central Europe requires improving the quality of existing roads in all its segments. Length of the road is about $17 \mathrm{~km}$ long, and has plenty of narrow sections and sharp bends, which will in some areas be extended and corrected curve. On the final part of the route across the bridge on the river Tara will be established to connect to the same traffic route, which still goes through Montenegro to Albania.

In the eighties, the investigation of the route of the road, as well as the construction of power plants in the upper Drina River Basin. The level of exploration for road route is not appropriate, because it is necessary to increase the degree of exploration along the route, which is in line with the physical planning documents. The complexity of the geological structure and the importance of roads and facilities along the route require detailed geological research, which will define the characteristics of the terrain.
\end{abstract}

Keywords: route roads, facilities along the route, characteristics of the terrain, the terrain of exploration 